\title{
The contemporary culture in medical school and its influence on training doctors in ethics and humanistic attitude to the clinical practice
}

\author{
Izabel Cristina Rios ${ }^{1}$
}

Published online: 18 February 2016

(C) Springer International Publishing AG 2016

\begin{abstract}
Values and attitudes are strongly influenced by the subjective elements of the organizational culture of the medical school. The objective of this research was to better understand the medical school environment and the difficulties in training doctors in humanism in clinical practice. Qualitative research focused on subjective aspects of the teacher-student relationship, such as ethics and respect for differences, was conducted in a traditional Brazilian medical school. We used the technique of ethnographic observation and interviews with students and teachers. The data were analysed according to three categories: 1. self and other, 2. misuse of technology, and 3. models of teacher-student interactions. Over 12 months, we observed 22 teachers and 128 students (8 groups of 14-18 students), and we interviewed 9 teachers and 19 students, who were recognized as key-interviewees. Our analyses revealed that the medical school environment enables doctors and medical students' feelings of intellectual superiority, selfish and excessive competitiveness; inability to see the patient as a whole; overvaluation and excessive use of technology; role modelling of nonempathic behaviours; and behaviours showing disrespect, discrimination, and violence. These findings reveal attitudes that hamper the doctor-patient relationship, and some underlying issues of critical importance to the humanistic training of medical students. This study shows the need for institutional humanistic values to be adopted and applied to everyone. Perhaps an educational process that uses ethics more than academic disciplines should be used as a method of thinking and acting, which may encourage institutional changes that improve medical education as a whole.
\end{abstract}

Izabel Cristina Rios

izarios@usp.br

1 Center of Humanization of Health Practices of Hospital das Clínicas da Faculdade de Medicina da, Universidade de São Paulo, R. Doutor Ovídio Pires de Campos, 225 - 6 andar - Cerqueira César, São Paulo, SP CEP 05403-010, Brazil 
Keywords Medical education - Humanization of health practices - Medical humanities · Qualitative research · Professionalism

\section{Introduction}

Writers see contemporary culture as a time of great scientific and technological development, as well as profound changes in people's behaviour (Lash 1985; Augé 1995; Giddens 1991). The individualism of the Modern Era has emerged as the contemporary form of narcissism: people are more focused on themselves and their personal achievements and lack a real interest in others, resulting in superficial and instrumental relationships (Habermas 1985). Thus, relational experiences may not constitute true encounters of individuals who are motivated by the same common objective of coming to an understanding and constructing something together. Habermas used the term 'instrumental action' to describe communication aimed towards obtaining a specific result of interest to one of the parties involved in a relationship and rejected the notion that this would be ethical and communicative action.

The dichotomy of science and humanism and the overvaluation and fascination with technology are also characteristics of contemporary society as a whole, which is reinforced in medicine (Schraiber 2008). Current medical practice occurs under scientific, technological and political-organization conditions that reduce the human existence to biological facts, a phenomenon known as technicism. In addition, issues of the ethics involved in using technology for a variety of purposes and the way in which medical work is organized at institutions are also important for good medical practice (Cassel 2007) .

Medical work is essentially relational work (Hundert et al. 1996; Rios 2010). An emotional conscience, empathy and communication are basic skills that compound the intersubjectivity in the medical profession (Hendelman and Byszenski 2014). Thus, the decrease in intersubjectivity in medical practice by the excessive use and overvaluation of technology and the reduction of the physician-patient relationship by technicism to a level of contact that is insufficient for good medical practice has been observed.

In traditional schools of medicine, some causes of the gap in the doctor-patient relationship are the focus on biomedical disciplines, teaching by accumulation, and insufficient ethical and empathic development during medical training. Since the 1960s, the disciplines of medical humanities (Brody 2009; Kuper 2007a) have been included in the undergraduate curriculum to improve humanistic education. These disciplines try to incorporate contributions from psychology, anthropology, communication, ethics, history, art and other themes of the humanities and human sciences into the theory and practice of medicine.

Several studies have shown that teaching ethics, empathy and communication skills improves the quality of the doctor-patient relationship (Hafferty and Franks 1994; Caldicott and Danis 2009; Yedidia et al 2003; Eriksson et al 2007; Eckles et al. 2005). The literature also shows that humanities disciplines in the medical curriculum are necessary for humanistic education but are not sufficient. Subjective aspects (Vagan 2009; Kuper 2007b) of the medical school environment are also very important in building a professional identity and behaviour.

Through observation of teachers in classrooms, laboratories, and especially in clinical work with patients (Rios 2010; Wright and Carrese 2001; Donetto 2010), the 
student learns how to be a doctor. This process occurs through conscious and unconscious identification (Rios 2010; Goldberg 2000) with attributes, properties, or partially subjective aspects in teaching and learning scenarios.

Medical school environment carries a tradition that is manifested in values, beliefs and behaviours that comprise a powerful array for the construction of identity for students and to which doctors constantly return to during their working life. Medical tradition has peculiar features as follows: (1) learning by pressure, stress and suffering that characterizes the ritualistic passage of the profession; (2) the hierarchical structure (not only based on knowledge, which is highly valued among doctors, but also on power); (3) the friendly alliance that unites doctors; and (4) the choice of profession for altruistic reasons (Hundert et al 1996; Rios 2010; Beckman 2015). These elements, in their abstract nature, are less obvious but are no less important to the establishment of medical identity, especially regarding ethical conduct and the capacity for empathy and communication.

To better understand the influence of elements of contemporary culture and medical tradition in the construction of being a doctor in medical training and the difficulties in medical practice, in 2010, we concluded a qualitative study in a medical school. We focused on the teacher and student relationship, as well as some subjective aspects that hamper humanistic interactions based on ethics, good communication and respect for differences. The results of this research showed some behaviours and underlying aspects of an organizational culture that needs to be changed to develop more humanistic attitudes in medical school.

\section{Methods}

To deepen the understanding of the subjective factors involved in relationships in medical training, we chose a qualitative research design (Denzin and Lincoln 2000). As a case study, we chose a medical school in the state of São Paulo, which offered a standard level of education and a good quality model of technical and scientific medicine.

We focused on the areas of internal medicine and surgery, which are considered to be the paradigmatic core of medical education. For the research subjects, we chose teachers in these subjects and undergraduate students from years one to six.

We used the technique of ethnographic observation supplemented by interviews with students and teachers to obtain empirical data (Geertz 1973). We chose to observe interpersonal relationships during internship because this is a phase of practical training for undergraduates where they learn more intensely the values and models of professional conduct. In Brazilian medical schools, the internship corresponds to the last two years of undergraduate studies (fifth and sixth years). Students are distributed into small groups and move through inpatient and outpatient departments. In these stages, teaching takes place predominantly through observing the work of doctors, supervised practical activities and discussions of clinical cases.

In the interviews, we used an open script, allowing us to be flexible and listen to the subjects to discern their relationships in specific contexts and through their own words. The script covered the following:

- Images and ideas about yourself and others

- Values in general and moral values (or lack of) 
- Being a doctor, teacher, or medical student

- Importance and use of technology in medicine

- How to provide patient care

- Relationships between people (teachers, students and patients)

- Situations of violence in medical training

This study was approved by the Ethics Committee in Research of the School of Medicine.

\section{Results}

Over 12 months of fieldwork, we observed 22 teachers and 128 students (8 groups of 14-18 students), and interviewed 9 teachers and 19 students who were chosen during the observation and were characterized as good respondents according to the qualitative methodology ${ }^{21}$ (Table 1).

These data were founded on both observations and interviews. The data were analysed by three empirical-analytic categories: self and other, misuse of technology and models of human interactions. This analysis was verified by triangulation, which is a method of measuring the reliability of the results in qualitative research. The three categories of analysis and main empirical results are summarized in Table 2.

\section{Interpretative analysis of empirical data}

\section{Self and others}

A high investment in self-identity is apparent in students and teachers. Belief in intellectual, social or any type of superiority also appears several times. It could be the origin of the behaviour of self-sufficiency, excessive competition and a disregard for others. We realize that difficulties in intersubjectivity arise from this common behaviour in contemporary society.

Medical students demonstrate typical behaviours of the culture of narcissism (Ronningstam 2005), such as an enhancement of the body, vanity, selfish, unwillingness to act in groups, racial prejudices, emotional detachment and little involvement

Table 1 Research fieldwork

\begin{tabular}{llll}
\hline Technique & $\begin{array}{l}\text { Undergraduate } \\
\text { level }\end{array}$ & Persons & Time \\
\hline $\begin{array}{c}\text { Ethnographic } \\
\text { observation } \\
\text { Interviews }\end{array}$ & Internship & 22 teachers and 128 students & 12 months \\
Interviews & Years one to six & $\begin{array}{c}9 \text { teachers; } 5 \text { in internal medicine and } 4 \text { in } \\
\text { surgery } \\
19 \text { students; } 3 \text { from years one to five and } 4 \text { in } \\
\text { year six }\end{array}$ & $\begin{array}{c}22 \text { h of } \\
\text { interviews }\end{array}$ \\
& Years one to six & \begin{tabular}{c} 
interviews \\
\hline
\end{tabular}
\end{tabular}


Table 2 Subjective aspects of interpersonal relations in medical school

\begin{tabular}{|c|c|}
\hline ategories of analysis & Empirical results \\
\hline Self and others & $\begin{array}{l}\text { Feeling of superiority } \\
\text { Selfish } \\
\text { Excessive competitiveness } \\
\text { Isolation and self-sufficiency } \\
\text { Consumerism } \\
\text { Strong economic ambition and social projection } \\
\text { Enhancement of the body } \\
\text { Little ability for further reflection, superficial thoughts and emotions } \\
\text { Low self-criticism and difficulty in asking for help } \\
\text { Difficulty in accepting the unfamiliarity of the other and its differences } \\
\text { Little involvement with others } \\
\text { Disregard for others } \\
\text { Disregard of the other as subject }\end{array}$ \\
\hline Misuse of technology & $\begin{array}{l}\text { Biomedical model (vision focused on disease) } \\
\text { Work organization similar to the manufacturing model } \\
\text { Excessive use of technology } \\
\text { Less investigative clinical work }\end{array}$ \\
\hline $\begin{array}{l}\text { Models of teacher-students inter- } \\
\text { actions }\end{array}$ & $\begin{array}{l}\text { Centrality of the teacher in the educational process } \\
\text { Students as passive recipients of content } \\
\text { No procedural guidelines defining ethical conduct } \\
\text { Lack of agreed principles for teacher behaviour } \\
\text { Disregard of the student } \\
\text { Situations of violence, embarrassment, fear and humiliation } \\
\text { Abuse of hierarchical power } \\
\text { Student behaviour showing disrespect, confrontation and vandalism } \\
\text { Learning through suffering and fear as a rite of passage } \\
\text { Few situations of practices that allow communication (discussions in } \\
\text { small groups) }\end{array}$ \\
\hline
\end{tabular}

with others, strong economic ambition and social projection, competitiveness, excessive use of alcohol, little ability for further reflection and superficiality, consumerism, low self-criticism and difficulty in asking for help due to feelings of self-sufficiency and little life experience and immaturity. Nevertheless, the teachers stated that (as we have seen) students would be able to respond maturely when in educational situations that require it.

The professor of medicine is a central figure in medical training. In general, he or she is a physician who transmits his/her knowledge to students but does not have formal training to work as an educator. The notion of teaching comes from his/her own experience as a student within the model of traditional (Good 1994) education. In this model, the teacher is the subject of the action, and the student is the passive recipient of content (Freire 2000). The teacher has great power, which is exercised according to his/ 
her personality, on a scale ranging from empathy and respect to tyranny and humiliation of the student.

This model of education centred on the teacher does not offer a true role for the student as a subject (Spruijt et al 2013). Instead, students are treated as an object that, in a harmful sense, allows the teacher to narcissistically display his/her knowledge. For example, there are situations in which the hierarchy appears in the relationship between student and teacher, demonstrating to the student that the difference in status is not based on differences in knowledge, but differences in power.

The attitude of omnipotent and tyrannical masters in education creates embarrassment, fear and humiliation for the student. Where differences are perceived in terms of inferiority (whether for students or patients) this can result in the practice of "small abuses" and "jokes" where rights are abolished, and violence becomes natural; an attitude of "survival of the fittest".

Seeing the different other as a subject or as an object begins with the teacher-student relationship and continues later in the doctor-patient relationship. The treatment of the other as someone devoid of desire, autonomy and the exercising of rights and duties occur in different situations. The most striking is the situation in which the doctor reduces the patient to an instrument to use as an anatomical specimen for demonstration. As noted, this practice is still common in medical training, particularly in surgery. For some students, such scenes are embarrassing, traumatic and "unforgettable", but for some of the students, it is seen as a natural and expected situation arising from the contingencies of teaching.

\section{Misuse of technology}

These behaviours, which lead to serious consequences in interpersonal relationships, have the biomedical model (Good 1994) as one of their causes. In this model, the focus is on disease and the anatomical and physiological body. This model and the excessive number of daily visits that each physician performs allow medical work to be organized according to the manufacturing model, resulting in the loss of identity as a person. Importantly, not only does the patient lose his/her position as the subject, but the physician also loses his as both are treated as parts of the organizational machine.

The shortcomings of the biomedical model appear in the low satisfaction expressed by patients, whose health problems are not resolved by the technical approach. These patients repeatedly return with other complaints. The body, in its psychic dimension marked by history, culture and social determinations, claims answers in the intersubjectivity of medical patients' relations.

In the view of some teachers, the biomedical model takes technology beyond its precise and proper use. They argue that technology is necessary but is used to excess because it encourages doctors to shorten their work with patients, or because the patient does not feel well treated without it. Technology is a way to work faster in a less investigative clinical setting, where questions are not answered through communication, but by laboratory tests. Thus, it reduces the empathy, communication and human interaction that promote the humanization of care. We observed that communication can have the following different meanings: (1) a technical device for diagnosis and treatment, (2) the physician's moral duty, (3) taking responsibility to provide relief and comfort to another and (4) 
"Policy of good manners and self-defence" that would help the physician to address problems in the doctor-patient relationship.

Lying to the patient about his/her condition and prognosis often appears as a response, especially when the patient's questions require time, availability and emotional skills. For some students, this would be an abject and inhuman practice, but for others, the ends justify the means.

These shortcomings of the biomedical model, surprisingly, are not perceived by teachers and students as factors in the dehumanization of medicine. However, they recognize the lack of interest in the patient and the lack of good communication skills as the cause of dehumanization.

\section{Models of teacher-student interaction}

The relationships between teachers and students in teaching-learning scenarios are strongly pressed by the personal characteristics and values of each teacher. There are no procedural guidelines for conduct defining the agreed principles for teacher behaviour. This fact deserves attention because the pedagogical relationship is fundamental to the construction of identity and the teaching of the doctor-patient relationship.

The educational process is very teacher-dependent, and the centrality of the teacher creates an attitude of limited commitment to the formal curriculum in the student. The students appear to be more active and interested in social networks and activities that are considered to be more rewarding for their professional future, rather than in the knowledge and intellectual capital for their future profession.

Much of the formal teaching is provided by several teachers simultaneously, in an atomized manner, and almost anonymously. The educational environment is one of coldness and detachment. In addition, there is a lack of know-how on the part of teachers to establish dialogic relations and shared reasoning. Attitudes of disrespect are common: teachers do not acknowledge the students' opinions, and students seek confrontation with more flexible teachers.

Disregard for the student appeared in this study as a sub-product of the teacherstudent relationships based on authoritarian teachers and submissive students. To learn through suffering and fear as a rite of passage, showing strength, courage and persistence dates back to the origins of the profession, characterizing the physical and moral superiority of those who want to be doctors. Approval of this "method" appeared in the narrative of students and teachers, but it was strongly disapproved of by the most critical. It has no transcendent character but instead shows a lack of respect, lack of education, malice and lack of professional ethics.

The breakdown of communication, which deprives others of the role of subject and ignores their rights as a person created situations of violence and humiliation, degradation, abuse and harassment. Violence manifests itself in the form of disregarding the student, lying to patients, prejudice, racism, abuse of hierarchical power and vandalism. In all these cases, there is a common thread of the breakdown of communication and the use of force to impose one's will on others.

The hierarchy is a source of abuse of power. Those holding the power impose their narcissistic interests, regardless of what is best for the collective. From a philosophical view (Levinás 1998), this state, where the interests of the few outweigh the good of the many, is exactly the opposite of ethics. 
In the observations and reports obtained from the students, we find moments and scenes in which some teachers, mainly in surgery, not only ignore the principles of humanization (Rios 2010) but also act against them, triggering violence.

We recognized violent behaviours. This could be observed in the attitudes of patients who try to harm doctors and medical students. Conversely, we also observed patients being humiliated by doctors. Most of the patients neither reacted or sought institutional means for the protection of their moral integrity.

Among students, violent behaviour was also present in (1) sports competitions when, as in war, uncritically and without reason, they commit acts of vandalism and physical violence between rival groups; (2) students who abuse alcohol; (3) students who practice sado-masochistic "rites of passage" with younger colleagues; and (4) an environment of hostility and aggression. However, educational practices that allow communication have been widely recognized as the best by the students. For example: discussions in small groups led by teachers who are able to enter into dialogue. Such teachers have been identified as the best teachers, and also the best doctors because they are able to create spaces of intersubjectivity in teaching and in the healthcare service. They are persons who create conditions for medical training with humanization.

\section{Discussion}

The narcissistic culture of the contemporary times is reflected in medical school environment and manifests in the medical identity as a special feeling of superiority, individualism, competitiveness and isolation (Rios 2010; Ronningstam 2005). These elements, in their abstract nature, are not obvious but are important in the medical identity, especially regarding ethical conduct and the capacity for empathy and communication. The narcissistic culture can result in a difficulty to accept the unfamiliarity of the other, including violent acts and speeches.

The biomedical model and the inadequate organization of medical work reduce the time of the clinical encounter and turn the conversation into an instrumental act. In this model, vision is focused on disease and body, seeking only the facts, without emotion (Schraiber 2008). The result decreases the ethical dimension of the relationship and effectively curtails communication and dehumanizes the care.

In medical school, there are educational scenarios that expose students to a proper technical and medical attitude, but learning occurs primarily by models in practice, which operate independently, reinforcing or contradicting what is taught in the classroom (Hundert et al. 1996). Hence, training physicians with more humanism requires more than skill development and knowledge transmission. Subjective aspects of life in medical school are particularly important in the teaching and learning process.

The empirical manifestations of these reflexion points appeared clearly and sometimes forcefully in the teacher-student relationships in this study. All of the models for conduct presented here were implicitly accepted by the institution, which thus, in a specific way, legitimized them. Thus, one final question directed towards this organizational level would be appropriate: what values and conduct guidelines should the institution adopt in its discourse to be coherent with the curricular guidelines that, in its printed documents, prescribe consistent humanistic training for its students? 
This study shows the need for institutional values that apply to everyone, guiding actions in pursuit of the individual and the collective good. In philosophical terms, it is the practice of ethics. Ethics is the ability of the individual to judge and make decisions based on commonly accepted values (Cassel 2007). It means being able to articulate collective values in personal projects through a good understanding of these values, an understanding of others and an understanding of oneself. To introduce ethics as an exercise and method to achieve the right balance of technological excellence and humanistic values may be the way forward. Perhaps an educational process that uses ethics as a method may encourage institutional changes in behaviours that will improve medical education as a whole.

\section{Conclusions}

Today, the acquisition of ethical and relational competencies is one of the emerging topics within medical education. This is an educational process that involves specific disciplines of the humanities, adequate didactic-pedagogical methods and changes in institutional culture to emphasize ethics and rights. Thus, training physicians with more humanism requires more than skill development and knowledge transmission.

Aspects of contemporary culture, such as narcissism, technology and instrumental communication, are particularly important in the humanistic education of the medical student, once these elements hamper the recognition of the other person as different in a relationship guided by ethics. Technical preparation is not sufficient, even if based on technological excellence. It is necessary to introduce ethics as an exercise and method to obtain the right balance of theory and practice and the rationality and sensibility to constitute true encounters. In this respect, we signal here that there is a need for further studies with the aim of deepening the findings from this work and providing backing for interventions within the environment of medical education towards correcting and improving its pedagogical function.

\section{References}

Augé, M. 1995. Non places: introduction to an anthropology of supermodernity. London: Verso.

Beckman, H. 2015. The role of medical culture in the journey to resilience. Academic Medicine 90: 710-02.

Brody, H. .2009. Defining the Medical Humanities: three conceptions and three narratives. J Med Humanit 10. 1007/s10912-009-9094-4

Caldicott, C.V., and M. Danis. 2009. Medical ethics contributes to clinical management: teaching medical students to engage patients as moral agents. Medical Education 43: 283-289.

Cassel, E.J. 2007. Unanswered questions: bioethics and human relationships. The Hasting Center Report. 37 : 20-23.

Denzin, N., and Y.S. Lincoln. 2000. Handbook of qualitative research, 2nd ed. Thousand Oaks: Sage Publishing.

Donetto, S. 2010. Medical students' views of power in doctor-patient interactions: the value of teacher-learner relationships. Medical Education. doi:10.1111/j.1365-2923.2009.03579.187-196.

Eckles, R.E., E.M. Meslin, M. Gaffney, and P.R. Helft. 2005. Medical ethics in education: where are we? where should we be going? a review. Academic Medicine 80: 1143-1152. 13.

Eriksson, S., G. Helgesson, and A.T. Höglund. 2007. Being, doing, and knowing: developing ethical competence in health care. Journal Academic Ethics 5: 207-226. 
Freire, P. 2000. Pedagogy of freedom: ethics, democracy and civic courage. Lahan: Rowman \& Littlefield. Geertz, C. 1973. The interpretation of cultures. New York: Basic Books, Inc.

Giddens, A. 1991. Modernity and self-identity: self and society in the late modern Age. Stanford: Stanford University Press.

Goldberg, P.E. 2000. The physician-patient relationship - three psychodynamic concepts that can be applied to primary care. Archives of Family Medicine 9: 1164-8.

Good, B.J. 1994. Medicine, rationality, and experience: an anthropological perspective. New York: Cambridge University Press.

Habermas, J. 1985. The theory of communicative action. Boston: Beacon.

Hafferty, F.W., and R. Franks. 1994. The hidden curriculum, ethics teaching, and the structure of medical education. Academic Medicine 69: 861-871.

Hendelman, W., and A. Byszenski. 2014. Formation of medical student professional identity: categorizing lapses of professionalism, and the learning environment. BMC Medical Education 14: 139.

Hundert, E.M., D. Douglas-Steele, and J. Bickel. 1996. Context in medical education: the informal ethics curriculum. Medical Education 30: 353-364.

Kuper, A. 2007. The intersubjective and the intrasubjective in the patient -physician dyad: implications for medical humanities education. Medecine Humanities 33: 75-80. doi:10.1136/jmh.2006.000252.

Lash, C. 1985. The minimal self: psychic survival in troubled times. New York: WW Norton.

Levinás, E. 1998. Entre nous - essays on thinking-of-the-other. New York: Columbia University Press.

Rios, I.C.2010. Subjetividade Contemporânea na Educação Médica: A formação humanística em Medicina. (Contemporary Subjectivity in Medical Education: Humanistic Training in Medicine). PhD Thesis. Faculdade de Medicina da Universidade de São Paulo.

Ronningstam, E.F. 2005. Identifying and understanding the narcissistic personality. New York: Oxford University Press.

Schraiber, L.B. 2008. O médico e suas interações - a crise dos vínculos de confiança. (Doctors and their Medical Interactions - the Crisis in the Relationship of Trust). São Paulo: Hucitec.

Spruijt, A., Wolfhagen, I., Bok, H., Schuurmans, E., Scherpbier, A., Van Jaarsma, D. 2013. Teachers' perceptions of aspects affecting seminar learning: a qualitative study. BMC Medical Education, 13, 22. http://www.biomedcentral.com/1472-14 6920/13/22

Vagan, A. 2009. Medical students' perceptions of identity in communication skills training: a qualitative study. Medical Education 43: 254-259.

Wright, S.M., and J.A. Carrese. 2001. Which values do attending physicians try to pass on to house officer? Medical Education 35: 941-945.

Yedidia, M.J., C.C. Gillespie, E. Kachur, M.D. Schwartz, J. Ockene, and A.E. Chepaitis. 2003. Effect of communications training on medical student performance. JAMA 290: 1157-1165. 